\title{
Does the school cutoff date cause the disadvantage for children born in July and August?
}

\author{
Chunni Zhang ${ }^{1^{*}}$ and Yu Xie (2,3 $^{2}$
}

\author{
* Correspondence: \\ chunnizhang@pku.edu.cn \\ ${ }^{1}$ Department of Sociology, Peking \\ University, Beijing, China \\ Full list of author information is \\ available at the end of the article
}

\begin{abstract}
Compulsory education systems usually specify a cutoff date regulating the precise age for entry into primary school. Existing literature from the USA and Europe has demonstrated that children born just before the cutoff date are disadvantaged in academic performance and has formalized this phenomenon as the "age position effect." A recent study by Liu and Li (Sociol Stud 6:169-245, 2015) reported similar findings for China. Our study, however, challenges Liu and Li's conclusion by examining the long-term effects of birth month on socioeconomic attainment and the compliance rate regarding the cutoff date. Using the 2005 1\% Mini-census Survey and the 1992 National Sample Survey of the Living Situation of Chinese Children, we found a significant variation in socioeconomic achievement by birth month in adulthood in ways that differ from those reported by Liu and Li. In addition, we found compliance to be affected by both birth month and parental characteristics. In conclusion, our article proposes parental self-selection as an alternative explanation for the cutoff date effect.
\end{abstract}

Keywords: Age position effect, Compulsory Education Law in China, Enrollment cutoff date, School starting age, Life-course perspective

\section{Background}

Mainstream research on social stratification usually emphasizes the consequences of structural mechanisms such as family's social socioeconomic status, class, gender, and race on social mobility, while acknowledging the important roles of choices made by individual actors in life-course transitions. From the life-course perspective, a life course can be viewed as an interweaving of age-graded trajectories consisting of a series of critical life events or transitions ranging from school entry to retirement. What happens in an early transition can affect not only the outcomes directly resulting from this transition but also later outcomes by affecting subsequent transitions (Elder 1985, 1994). If a transition is timely in relation to age norms or biological timing, it is usually associated with beneficial outcomes; if the transition is ill-timed, this may be deleterious (Elder 1994). In a modern society, an individual's life course is inevitably shaped and standardized by social institutions and policies (Mayer and Müller 1986). Institutionalized age markers, such as legal age, often regulate the timing of a transition. Nevertheless, individuals can still vary substantially within a particular group

(c) The Author(s). 2018 Open Access This article is distributed under the terms of the Creative Commons Attribution 4.0 International License (http://creativecommons.org/licenses/by/4.0/), which permits unrestricted use, distribution, and reproduction in any medium, provided you give appropriate credit to the original author(s) and the source, provide a link to the Creative Commons license, and indicate if changes were made. 
defined by legal age limits. Variation in an age group at an early stage of life could also have enduring consequences for one's later achievement and well-being. One transition that may trigger such an impact is school entry, a common transition experienced by almost all children in the world.

Most countries specify a minimum age and an enrollment cutoff date for school eligibility. Only when a child reaches the legal minimum age by the cutoff date is he or she eligible to start schooling in a given year. In most educational systems, the enrollment age rule ensures that young children in the same school cohort will be similar in age so that teaching can be more easily standardized and routinized. Moreover, the enrollment age rule in countries like China also provides a clear legal standard protecting children's rights to education. The exact enrollment cutoff date, however, is somewhat arbitrarily chosen, imposing uniform school-entry timing even when young children of the same age may vary in school readiness, leading to academic advantages or disadvantages for children born in different months (Bedard and Dhuey 2006; Dhuey and Lipscomb 2010; McEwan and Shapiro 2008; Mühlenweg and Puhani 2010). In a recently published article entitled "Children Born in July and August: A Study on the Age Regulation of Primary School Admission and Student's Education Access and Development," Liu and Li (2015) reported how birth months, thought to be randomly distributed, affected the academic performances of adolescents due to the rule of minimum age and enrollment cutoff date specified by the Compulsory Education Law in China. They found that high school students born in July and August, being the youngest students given the enrollment cutoff date in August, had more academic problems, lower levels of self-confidence, and greater likelihood of being addicted to internet games. As a result, July-August-born students were found to be less likely to be admitted to key high schools when compared to September-October-born students, the oldest group at the time of initial school entry, having been born in the months immediately after the cutoff date (Liu and Li 2015).

Liu and Li's study was the first in China to show, using empirical evidence, the effect of school enrollment cutoff date on educational outcomes. Taking a more ambitious step, the authors further claimed that "[the enrollment cutoff date] as a policy at the micro level will ultimately result in educational inequality in China through age-related differences in early school performance, classroom practice and competitive school transitions" (Liu and Li 2015: 188). Furthermore, they suggested that educational authorities should change the rule on minimum age for school eligibility and the enrollment cutoff date.

However, Liu and Li's study had three limitations. First, they attributed the performance difference between children born in the months before and after the cutoff date to an effect of age position alone. The age position effect refers to age-related differences in performance attributable to child development. Children who are slightly older usually have developed further in cognitive, physical, and psychological domains than those who are younger, but only for the first few years, after which the age position effect diminishes as the children grow up. Moreover, a large body of research on the phenomenon of age position effect is in sports (Baxter-Jones and Helms 1994; Edwards 1994; Musch and Grondin 2001). It has been found that players being born in early months in the same competition ages have competitive advantages in being selected to top teams. Unlike voluntary participation in sports, however, compulsory school attendance keeps weaker children in the educational system for more years. Therefore, 
younger children still have a chance to eventually catch up with their older peers. Unfortunately, Liu and Li's study only observed age-related performance differences among high school students using a regional survey with a cross-sectional design. The researchers could not determine the actual performance gap between the two groups of children at the time of school entry. We cannot rule out the possibility that the gap had narrowed from primary school to high school. Without longitudinal data, it is too early to claim any long-term disadvantage for children born just before the cutoff date.

Second, Liu and Li excluded those cases for students who did not comply with the enrollment cutoff date, which accounted for $43.9 \%$ of the original sample. This portion should not be ignored, however, as compliance with the enrollment cutoff date may be selective with respect to birth month or family background. Economists often use the child's birth month relative to the enrollment cutoff date as an instrumental variable (IV) by which to determine the effect of school starting age. This practice is based on the assumption that the month in which a child is born is randomly distributed and exogenous and that all parents follow the cutoff date to schedule their child's school entry regardless of the child's personal and parental characteristics. If this assumption is violated, it will be problematic to use the IV method to identify the effect of school starting age. Given the high degree of noncompliance present in Liu and Li's regional data, the validity of their findings is called into question.

Our study aims to answer two questions: (1) Does the cutoff date effect on educational outcome persist into adulthood? and (2) To what extent do Chinese parents and children comply with the enrollment cutoff date? To examine the long-term consequences of the cutoff date, we use China's 2005 1\% Mini-census Survey to compare socioeconomic achievements between individuals in their mid-20s who were born in the months either before or after the cutoff date. To answer the second question, we utilize data from the 1992 National Sample Survey of the Living Situation of Chinese Children to explore the effect of the cutoff date and family characteristics on school starting age. Rather than rushing to conclude that school entry at an older age has any persistent beneficial effect on outcomes, we attempt to offer parental self-selection as an alternative explanation for the discontinuity of achievement around the enrollment cutoff date, at least for China.

The article proceeds as follows. The literature review section summarizes the previous debate over the mechanisms through which the cutoff date may affect children's educational outcomes and also introduces the rules of school enrollment age specified by the Law of Compulsory Education in China. The methods section describes the data and our empirical strategy. The section of results contains the examination of the birth-month variations in adult outcomes and in school starting age, followed by our alternative explanation for the cutoff date phenomenon. The final section presents the discussion and conclusions.

\section{Literature review}

\section{The cutoff date phenomenon in education}

Varying academic performance associated with enrollment cutoff date was noted as early as the 1960s. Education researchers (mainly in the United Kingdom) compared academic performances among students who were born in different seasons and found 
that those born in the season before the cutoff date performed worse than those born in the season after the cutoff date (Pidgeon 1965; Shearer 1967; Thompson 1971). These findings, however, were neither conclusive nor solid, given the small samples and regional data used in the studies. The mechanism behind the cutoff date phenomenon also remained unclear.

Interest in the issue of enrollment cutoff dates has recently emerged in economics. Economists attempt to find out how small variations in the timing of early childhood education may lead to different processes of human capital accumulation later in life. More specifically, interest centers on the association between schoolstarting age and children's educational outcomes. Since the actual school starting age is endogenous, child's birth month relative to the enrollment cutoff date becomes a good IV by which to determine the effect of school starting age. Because children born after a particular cutoff date are required to start school almost one year later than children born just before the date, this delay is exogenous and independent of family socioeconomic characteristics. Most findings show that children born after the cutoff date perform better on tests, are less likely to be diagnosed with a learning disability, and are more likely to succeed in educational transitions than children born before the cutoff date (Bedard and Dhuey 2006; Dhuey and Lipscomb 2010; Fredriksson and Öckert 2005; McEwan and Shapiro 2008; Mühlenweg and Puhani 2010; Puhani and Weber 2008). Although most of these studies come to the conclusion that school-entry age has an effect, they leave the issue unresolved as to whether the effect is a matter of relative age or of absolute age, a result of older children obtaining more preschool skills or of their having faster learning rates.

The relative age effect argues that children starting school in the same year are positioned in different age groups: the youngest group includes those who have birthdays just before the cutoff date and enroll in school as soon as they are eligible, while the oldest group consists of those who have birthdays after the cutoff date and enroll in school almost one year older. Older children usually are more mature and have accumulated more preschool skills when they start school. As a result, their relative maturity and more advanced preschool skills enable them to perform better on tests at lower grades than do younger children. This is also called the "age-at-test effect." Since a year of maturity represents a more significant difference in learning among young children than among adolescents and adults, however, these age-related differences should fade away as the children grow up (Elder and Lubotsky 2009).

In contrast with the age-at-test effect, other researchers argue for an effect of absolute age for school entry. They argue that children may not be prepared cognitively, physically, and psychologically for formal learning in school unless they reach a certain absolute age. The higher level of school readiness among older children benefits them not only in their initial adaptation to school but also in learning in later grades. As a result, older children always end up with more human capital. Supporters of both the relative age effect and the absolute age effect agree that children born after the cutoff date benefit from a higher level of maturity, but they differ in whether their advantage derived from a higher level of maturity at the initial stage persists into later life (Elder and Lubotsky 2009). This debate is largely empirical, and the existing findings are mixed and inconclusive. 
To some extent, the persistence of the age position effect depends on which specific context is under examination. The practice of the educational system can either reinforce or mitigate the age position effect. For instance, students in Germany are selected into either academic or vocational tracks as early as the end of primary school. Hence, the effect of school-entry age is found to be larger and more lasting in Germany than in other countries where tracking occurs much later (Mühlenweg and Puhani 2010; Puhani and Weber 2008). Bedard and Dhuey (2006) compared the age position effect of 19 OECD countries. They found that the relative age premium is smaller in countries where retentions are more common and not significant in Denmark and Finland, where formal curriculum-based education begins at relatively older ages.

In addition to the educational system, teacher's assessment also plays a role in student performance. Teachers tend to evaluate older children more positively (Shearer 1967), expect more from older children, and assign older children more challenging tasks (Daniels et al. 2000). In contrast, younger children are more likely to be evaluated for, and even diagnosed with, learning problems (Dhuey and Lipscomb 2010; Gledhill et al. 2002).

Some educational settings may reinforce the age position effect, while others may produce an opposite effect. The school entry law in the USA defines age 16 as the minimum age for leaving school and students cannot legally drop out until they reach their 16th birthday. The minimum age for leaving school and the cutoff date jointly produce an effect on the possibility of dropout: students born after the cutoff date start school at older ages and reach their minimum age for leaving school before they finish secondary school. As a result, they receive fewer years of schooling on average than those who start school at younger ages, as the latter group are required to stay in school longer (Angrist and Krueger 1991, 1992).

In short, the existing literature does not allow us to draw simple, blanket conclusions about the age position affect. Whether and how cutoff dates affect children's education outcomes could vary depending on the actual institutional environment. From this perspective, it is worthwhile to try to understand the educational system in China, as this is the social context in which we evaluate the cutoff date effect.

\section{The compulsory education system in China and its age rule for school eligibility}

China introduced a 9-year compulsory education system when China's Compulsory Education Law went into effect on July 1, 1986. The law entitled all children in China ages 6-15 to receive tuition-free primary and lower-secondary education for a total of 9 years (usually 6 years in primary school and 3 years in lower-secondary school).

The Compulsory Education Law regulates the timing of school entry by setting a legal minimum age at which children can begin school and an enrollment cutoff date. It sets age 6 as the eligible age, but it allows age 7 as the threshold for less-developed regions. In practice, the choice of 6 or 7 as the minimum age for school entry was made by local governments at the city level. During the initial years of the law's enactment, age 7 was widely chosen as the threshold in most provinces, but the threshold gradually moved to age 6 as most provinces amended the rules for implementation after 2000. The details of the Compulsory Education Law specify that children become eligible for school entry when they reach the legal minimum age before the beginning 
of the school year. Since September 1 is officially the first day of the school year across the country, August 31 is the nationwide cutoff date. In principle, children who have reached their 6th (or 7th) birthday before August 31 should immediately be enrolled in primary school on September 1 of the same year, while those born that year but after August 31 should wait until the following school year.

Enforcement of the Compulsory Education Law, however, has varied across regions. Administratively, the age rule of school entry is monitored by local government educational authorities. Fifteen days before the beginning of each school year, local government educational authorities send a notification letter requesting parents whose child has reached/will reach the school-entry age by August 31 of that year to enroll the child in primary school. If the child requires an enrollment delay, the parents or other guardians must receive approval from education bureaus at the county level or above. The law has no bearing if the parent wants the child to start school ahead of schedule. Usually, schools do not enroll underage children, but not all schools strictly adhere to the age rule. Many Chinese parents want their children to start school as early as possible. They may use personal relationships or pay extra fees to enroll their underage children in school ahead of schedule. As a response, educationists write articles advising parents not to do this and telling them about the negative consequences of starting school too early. Nevertheless, compliance with enrollment cutoff dates in China, to be analyzed below, seems to be lower than in other countries.

The level of compliance matters for the validity of the estimates when birth month is used as an IV to estimate the causal effect of school starting age on outcomes. If compliance is perfect, the IV estimate can be interpreted as an approximation of the average treatment effect (Black et al. 2011). If compliance is modest, the IV estimate is the local average treatment effect (Angrist and Pischke 2009). However, if compliance is low, the IV may not be a good estimate of treatment effect.

Along with the compliance issue, other features of China's compulsory education system also have implications for the effect of school starting age. Despite there being no tracking during the compulsory education years, competitions at the primary and lower secondary levels are still very intense in China. Grade repeating is not encouraged and is stigmatized, and the school system offers no special programs or therapy services for students with learning difficulties. In addition, China's school education is largely exam-oriented. Access to compulsory educational schooling is claimed to be universal, but the quality of schools and teachers varies significantly. Students compete in exams for access to better schools or key classes that could significantly improve their prospects of transitioning to education at higher levels. Schools and teachers are also evaluated by student performances on unified examinations, and thus they have an incentive to focus on better-performing students at the expense of those who fall behind. Consequently, if there is an age position effect, we expect that the initial disadvantage of poorly performing younger students may extend into later years.

\section{An early timing hypothesis}

Although an age position effect predicts a disadvantage for the youngest students at school, being the youngest may not always be penalized. From the life-course perspective, 
making an early transition may be preferable (Elder 1998). If a transition is beneficial, the earlier an individual makes the transition, the more he/she can benefit from it. If a transition is harmful, the individual who experienced it at a younger age has more time to recover from it. Research on World War II veterans in the USA reveals that servicemen who entered the service at a younger age were most likely to maximize the support of the G.I. Bill for higher education, while late entrants were least likely to do so and usually suffered from career or marital disruptions (Elder 1987).

In the case of school entry, individuals who started school early will finish their education at younger ages and enter the labor market earlier. Hence, they acquire more work experience, stay in the labor market for more years (given the same retirement age), and have more time to make alternative life choices. A few studies have examined the long-term consequences of school starting age on life-time earnings, educational attainment in adulthood, and teenage birth (e.g., Black et al. 2011; Dobkin and Ferreira 2010; Fredriksson and Öckert 2005). These studies report a short-term age-related academic disadvantage for younger students but no long-term disadvantage in terms of labor market outcomes. A study by Fredriksson and Öckert (2005) even found that school starting age is negatively associated with life-time earnings. In addition, from the developmental perspective, children could benefit from early schooling, which enables them to learn faster and more efficiently than they do at home (Elder and Lubotsky 2009). We label this conjectured negative relationship between schooling age and later socioeconomic outcomes the "the early timing" hypothesis.

The early timing hypothesis does not reject the premium that late-entry children enjoy initially, but it suggests that the gains from late school entry are transitional and will be offset by time losses for accumulating labor market experience and experiencing alternative life events. Overall, however, the hypothesis states that early school entry is beneficial in the long run.

\section{Methods}

Given our two research questions, this study requires data containing a sample that is large enough to allow us to examine the variation in school starting ages and the variation in adult outcomes across birth months. It also requires retrospective information on an individual's school starting age and prospective information on his/her socioeconomic outcomes when he/she reaches adulthood. Unfortunately, there is no single dataset available in China that meets both requirements. Therefore, we use two datasets to answer the two questions separately.

The first dataset used in the study is the 2005 1\% Mini-census Survey in China. This survey was conducted by the China National Bureau of Statistics in November of 2005. Using a stratified, multistage, probability proportionate to size sampling approach, the survey obtained a sample of 17.05 million individuals, amounting to $1.31 \%$ of the population in China. The 2005 1\% Mini-census Survey in China collected the highest level of education from those of age 6 and above and monthly income from those of age 15 and above and employed or self-employed. We use these two variables as measures of socioeconomic attainment. Since the survey did not contain the year when individuals began the first grade of primary school, it does not allow us to directly examine the effect of school starting age on adult 
outcomes. Nevertheless, given that the timing of school entry is determined by a child's birth month when a cutoff date is introduced, we can use the birth month relative to the cutoff date as a proxy measure of school starting age. If adult socioeconomic outcomes by birth month change suddenly around the enrollment cutoff, we can infer that the school starting age has a lasting effect. Since the Compulsory Education Law was not implemented until 1986, the oldest cohort affected by the law were born in 1979. We thus further limit the sample to 3-year birth cohorts from 1979 to 1981, because most people from these cohorts had completed their education and entered the labor market by 2005 . After excluding cases with missing values on birth month, level of education, and monthly income, we obtain a sample of 104,481 men and women born between 1979 and 1981.

The second dataset we use in this study is the 1992 National Sample Survey of the Living Situation of Chinese Children. It is a cooperative project of UNICEF and the China National Bureau of Statistics. The survey was conducted in June 1992 and contained 180,800 urban children and 381,600 rural children born between 1977 and 1992 (ages 14 or below). The sampling in the survey adopted a stratified, multistage, probability proportionate to size approach. The sample was first allocated across 29 provinces, each of which was taken as a universe. Within each province, the sample was then stratified into urban and rural strata. The urban stratum was further divided into large, medium, and small cities and towns, and the rural stratum was further divided into flat areas, hilly areas, and mountainous areas. Finally, within each stratum, a children's sample was drawn according to population proportion. The survey contains birth information and educational history for each child. Since this study is concerned with primary school entry, we focus on children who had already started primary school at the time of interview. We exclude children who were dropouts or had never been enrolled in school, because their grade and enrollment level were not available. Cases with reporting errors about grades or enrollment level are also excluded. We finally obtained an analytical sample of 229,734 rural and urban children who started primary school between 1983 and 1991. Since the 1992 Survey of the Living Situation of Chinese Children is cross-sectional, it cannot provide any child outcomes after age 14. We only use the data to examine the distribution of school starting ages and factors associated with the timing of school entry.

Given the very large sample size of the 1992 Survey of the Living Situation of Chinese Children and the 2005 1\% Mini-census Survey, the results based on them should be considered close to the real distribution of school starting ages and the real distribution of adulthood outcomes in the population. If we observe that school starting ages vary across birth month in the 1992 Survey of the Living Situation of Chinese Children on the one hand, and socioeconomic outcomes vary across birth month in a similar way in the 2005 1\% Mini-census Survey on the other hand, we may infer a real relationship between school starting ages and adult achievement outcomes.

The timing of school entry, as measured by the actual age at which a child started school, is a key variable in our analysis. The actual school starting age is measured by the number of years from the child's birth month to August of the year in which he/she began the first grade of primary school (see Eq. 1). In Eq. 1, $\mathrm{AA}_{i}$ denotes the actual school 
starting age of individual $i$, and $\mathrm{YRB}_{i}$ and $\mathrm{MOB}_{i}$ denote the birth year and birth month of individual $i$, respectively. $\mathrm{YRS}_{i}$ denotes the year individual $i$ started primary school.

$$
\mathrm{AA}_{i}=\mathrm{YRS}_{i}-\mathrm{YRB}_{i}+\frac{8-\mathrm{MOB}_{i}}{12}
$$

The actual age of school entry is usually affected by the child's maturity and ability, parental choice, and family resources. But the variation of school starting age became less dependent on the child's and parental characteristics when the cutoff date and minimum age of school entry were introduced. These age rules provide an expected age of school entry, which is determined only by the child's birth month. Given that the cutoff date in China is August 31, the child's expected age of school entry $\left(E_{i}\right)$ is measured by the number of years from his/her birth month to the August of the year in which he/she reaches his/her 6th (or 7th) birthday before the enrollment cutoff date (see Eq. 2). In Eq. 2, we allow $S_{j}$, the legal minimum age of province $j\left(S_{j}=6,7\right)$, which varies across provinces.

$$
\mathrm{EA}_{i}=\left\{\begin{array}{c}
S_{j}+\frac{8-\mathrm{MOB}_{i}}{12}, \text { if } 1 \leq \mathrm{MOB}_{i} \leq 8 \\
\left(S_{j}+1\right)+\frac{8-\mathrm{MOB}_{i}}{12}, \text { if } 9 \leq \mathrm{MOB}_{i} \leq 12
\end{array}\right.
$$

In a situation in which the minimum age and cutoff date rules are strictly followed, a child's actual and expected ages of school entry should be identical. Figure 1 presents the expected school-entry age for children born each month if an age threshold of 6 was universally applied in all provinces. We can see from Fig. 1 that August-born children are the youngest and September-born children are the oldest in a given school cohort. The age gap between the two groups of children can be as large as almost one year. Based on the above features, we can compare the actual age of school entry and adult outcomes among children born in different months to see if the actual school starting age distribution and achievement distribution follow or deviate from that of the expected age distribution. If the distribution of achievement against the birth month deviates from the pattern in Fig. 1, we will question the lasting effect of school starting ages on outcomes. If the distribution of actual school starting age deviates from the pattern in Fig. 1, this indicates that there are cases of noncompliance with the

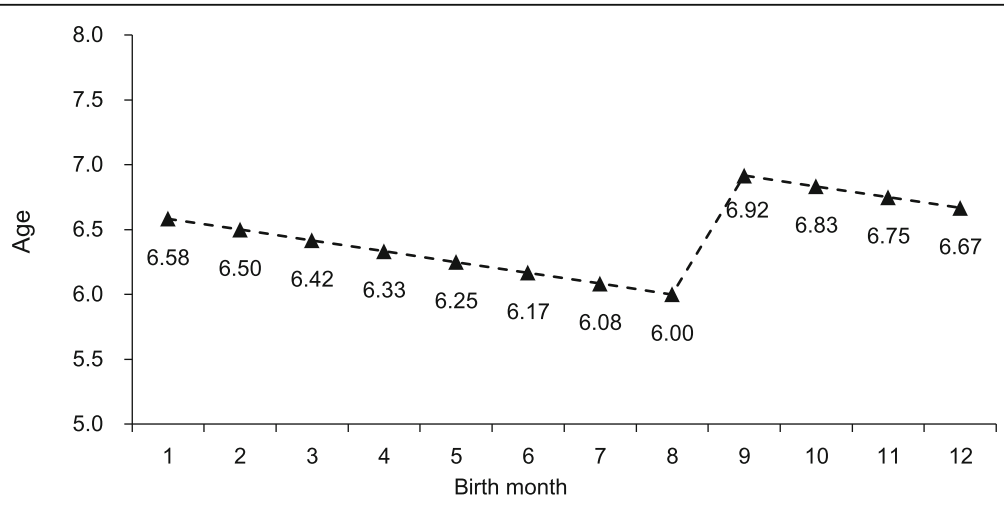

Fig. 1 Expected school starting age by birth month with an age threshold at 6 
cutoff date, which calls for more attention to the child's or parental selection on the timing of school entry.

\section{Results}

\section{Variation of adult achievements across birth month}

We begin by examining the impact of enrollment cutoff on achievements in individuals' mid-20s. The achievements are measured as educational attainment and monthly income. We use the 2005 1\% Mini-census Survey to examine the distribution of achievement variables against the birth month to see if the values change suddenly around the enrollment cutoff.

Figure 2 displays completed years of schooling by birth month. It reveals that individuals born in a month after the cutoff date obtained more years of schooling than those born in a month just before the date. Figure 3 displays average monthly income against birth month. It also shows that the individuals born just after the cutoff date earned more than those who were born just before the date. From both figures, we can see that individuals born after the cutoff date enjoy higher educational attainment and better incomes than those born before the date. The achievement gap between those born before and after the cutoff date is substantial: 0.3 years in schooling and 38 yuan in monthly income.

However, we note that the pattern of adult outcomes with birth month is not fully consistent with that of school starting age shown in Fig. 1. The highest socioeconomic attainments are not found among September-born individuals, but among those born in November. The lowest achievements are not found among August-born individuals, but among those born in March. These birth-month patterns of achievement differ from what is predicted from the age position effect, which expects September-born individuals to have the highest attainment as they were the oldest at the time of school entry, with August-born individuals having the most adverse outcomes, as they were the youngest. Our findings are not consistent with Liu and Li's. Instead of comparing academic performance for students born in each of the 12 months, they compared the outcomes by three groups of birth months: September to October, November to next

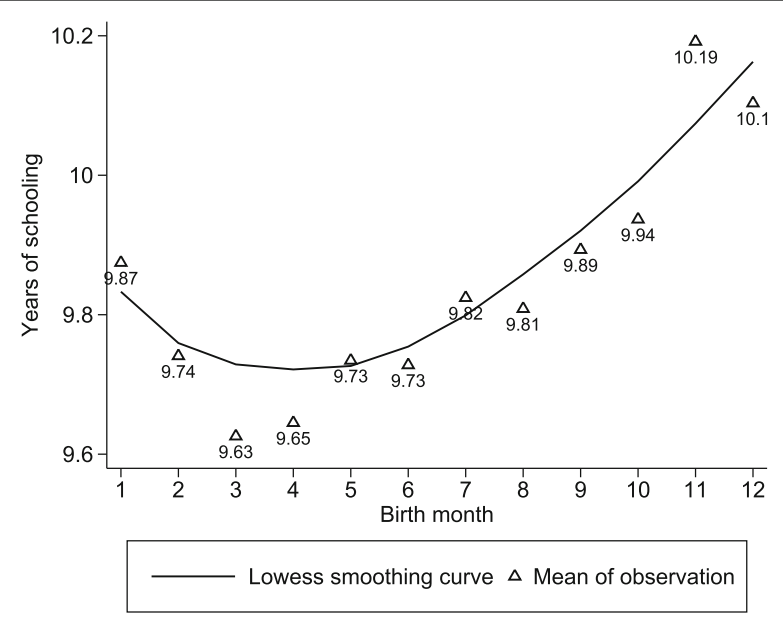

Fig. 2 Average years of schooling by birth month, for birth cohorts 1979-1981 


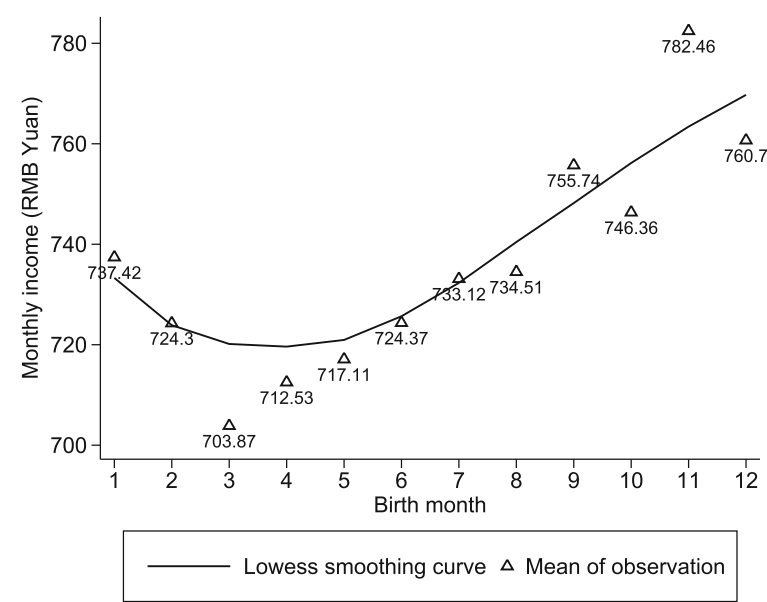

Fig. 3 Average monthly income by birth month, for birth cohorts 1979-1981

June, and next July to next August. But this grouping may be misleading and mask the real performance differences across months of birth. For example, they found that the performance of November-June-born students ranked between that of September-October-born students and that of July-August-born students, but this was probably because those November-June-born students were a mixture of the best-performing students and the worst-performing students. Moreover, even if their findings on school performance of high school students were correct, the evidence from the 2005 1\% Mini-census Survey shows that the early academic disadvantage of July-August-born children did not persist into adulthood.

However, there remains a puzzle as to why, if the phenomenon cannot be (fully) attributed to the age position effect, adult achievement outcomes do vary substantially by birth month. To answer this question, we turn to examining the relationship between school starting ages and birth month.

\section{Birth-month variation in the timing of school entry}

We use data from the 1992 Survey of the Living Situation of Chinese Children to examine the distribution of school starting ages against the birth month and explore factors associated with the timing of school entry.

First, we examine the societal impact of the Compulsory Education Law on school starting age. We divide the sample into three cohorts based on their school starting years: 1983-1985, and 1986-1988, and 1989-1991. Since the Compulsory Education Law was introduced in 1986, only the latter two school-year cohorts were affected by the minimum age and cutoff date. In Fig. 4, we plot the actual age of school entry by the child's birth month and the school-year cohort to see if the cutoff date in August creates a discontinuity of school starting ages between August-born and Septemberborn children in post-1986 school cohorts. For reference, we also plot the expected age of school entry based on the de facto provincial minimum ages and a nationwide cutoff date on August 31 in the same figure. As Fig. 4 shows, the school starting ages of children who started primary school before 1986 did not differ much between August and September. When we look at the distribution of school starting age for the two school 

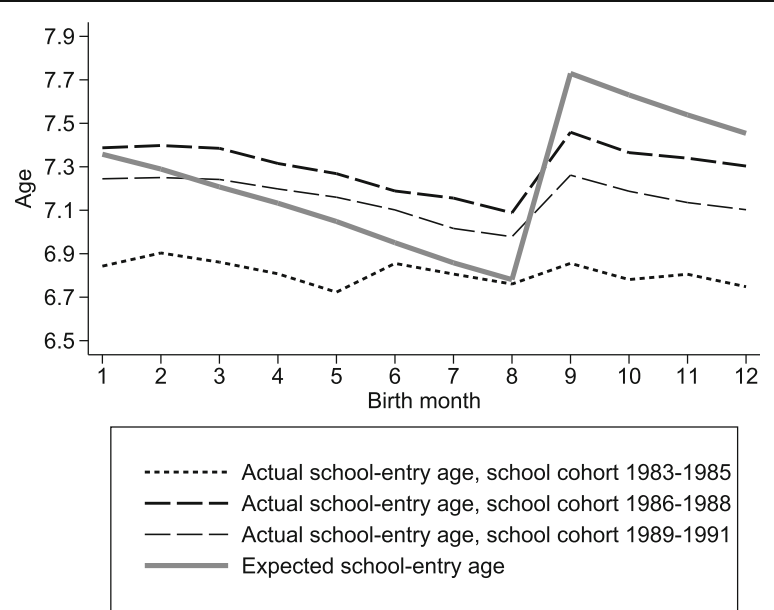

Fig. 4 Actual and expected school starting ages by birth month and by school cohorts

cohorts after 1986, we clearly observe the impact of the Compulsory Education Law: The actual age at which children started school gradually declined from January to August, then suddenly jumped upward in September, and then decreased in the remaining birth months. The only difference between the two post- 1986 school cohorts is that the average school entry age of the 1989-1991 school cohort was lower and closer to the age threshold at 6 , while that of the earlier school cohort was higher and closer to age 7. From this, we infer that more provinces began to adopt age 6 as the threshold for school entry with the promotion of the Compulsory Education Law over time.

Figure 4 provides graphical evidence of the Compulsory Education Law on school starting age. If we closely scrutinize Fig. 4, however, we note that the patterns of two post-1986 school cohorts did not fit the expected pattern for the expected age by birth month, shown in Fig. 1, as the observed age gap between August-born children and September-born children is not as large as the 1-year difference. These indicate that the cutoff date was not perfectly followed. Some children born after the cutoff date started school before they reached the minimum age, and some children born just before the cutoff date were delayed for school entry.

To further explore how the actual school starting age differs from the expected age, we classify children in the post-1986 school cohorts into three groups: on-time entrants for those who complied with the cutoff date and started school at an expected age, early entrants for those whose actual school starting ages were younger than their expected ages, and delayed entrants for those whose actual school starting ages were older than their expected ages. Figure 5 displays the percentages of on-time entry, early entry, and delayed entry by child's birth month for pooled post-1986 school cohorts. We find that compliance with the cutoff date depended on which month the child was born. Children born in a month right before the cutoff date, particularly in July and August, had high percentages of on-time entrants and delayed entrants. Children born after the cutoff date had an elevated percentage of starting school ahead of schedule.

We provide a statistical test for the finding that being born after the cutoff date increased the likelihood of early entry in Table 1. We use a binary indicator for starting school ahead of schedule for one year as the outcome variable and apply logistic regression models. The key independent variable, birth month, is measured as 11 dummy 


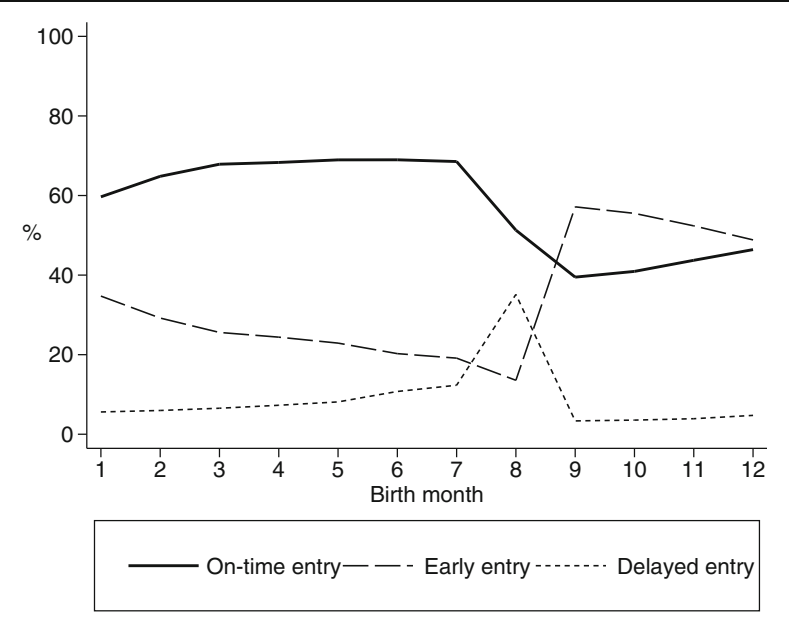

Fig. 5 Percent of on-time entry, early entry, and delayed entry by birth month

variables for each birth month from February to December in Model 1.1 and as a single dummy variable for birth months after the cutoff date (or in September-December) in Model 1.2. In both models, we control child and family characteristics, including child's sex, birth year, sibship size, mother's years of schooling, father's occupation, and urban residency. Both Model 1.1 and Model 1.2 show that being born in a month after the cutoff date significantly increases the odds of early school entry.

In Table 2, we examine more closely the finding that being born right before the cutoff date increased the likelihood of delayed entry. Again, we apply logistic regression models with a binary indicator for delaying school entry for one year as the outcome variable. We also control the same set of child and family characteristics. We start by adding 11 dummy variables for each birth month from February to December to determine the nonlinear effect of birth month on the likelihood of delayed entry. Model 2.1 shows that children born in the month before but close to the cutoff date (or born in May-August) were more likely to be held back than children born in earlier months or born after the cutoff date. For simplicity, we replace the 11 dummy variables of birth month in Model 2.1 with 2 dummy variables for being born between May and August and being born between September and December in Model 2.2. This model also reveals that being born between May and August is significantly associated with increased odds of delayed entry and being born between September and December is significantly associated with reduced odds of delayed entry.

The preceding analyses suggest that parents make decisions about children's school entry based on children's birth month relative to the cutoff date. However, breaking the age rule specified by the law may incur costly consequences, such as paying extra fees, changing the birthdate record, or using personal ties. We expect that families from better backgrounds have more resources with which to manipulate the timing of their child's school entry. We test this hypothesis by adding interaction terms of parental socioeconomic status and being born after the cutoff date to Model 1.2. The measures of parental socioeconomic status used for constructing the interaction terms are mother's years of schooling (Model 1.3) and father's occupation (Model 1.4). As Models 1.3 and 1.4 in Table 1 show, if a September-December-born child had a mother with more years of schooling or a father with a nonagricultural occupation, he or she was less 
Table 1 The logistic regression of early school entry for one year on child's birth month

\begin{tabular}{|c|c|}
\hline & Model 1. \\
\hline \multirow[t]{2}{*}{ Mother's years of schooling } & $0.038^{* *}$ \\
\hline & $(0.002)$ \\
\hline \multirow[t]{2}{*}{ Father's occupation: Cadre } & $0.520^{* *}$ \\
\hline & $(0.028)$ \\
\hline \multirow[t]{2}{*}{ Professional } & $0.461^{* *}$ \\
\hline & $(0.042)$ \\
\hline \multirow[t]{2}{*}{ Lower nonmanual worker } & $0.267^{* *}$ \\
\hline & $(0.024)$ \\
\hline \multirow[t]{2}{*}{ Manual worker } & $0.154^{* *}$ \\
\hline & $(0.019)$ \\
\hline \multirow[t]{2}{*}{ Birth month: February } & $-0.234^{* *}$ \\
\hline & $(0.028)$ \\
\hline \multirow[t]{2}{*}{ March } & $-0.423^{* *}$ \\
\hline & $(0.029)$ \\
\hline \multirow[t]{2}{*}{ April } & $-0.551^{* *}$ \\
\hline & $(0.030)$ \\
\hline \multirow[t]{2}{*}{ May } & $-0.611^{* *}$ \\
\hline & $(0.031)$ \\
\hline \multirow[t]{2}{*}{ June } & $-0.752^{* *}$ \\
\hline & $(0.032)$ \\
\hline \multirow[t]{2}{*}{ July } & $-0.843^{* *}$ \\
\hline & $(0.033)$ \\
\hline \multirow[t]{2}{*}{ August } & $-0.910^{* *}$ \\
\hline & $(0.032)$ \\
\hline \multirow[t]{2}{*}{ September } & $0.970^{* *}$ \\
\hline & $(0.025)$ \\
\hline \multirow[t]{2}{*}{ October } & $0.916^{* *}$ \\
\hline & $(0.024)$ \\
\hline \multirow[t]{2}{*}{ November } & $0.836^{* *}$ \\
\hline & $(0.025)$ \\
\hline \multirow[t]{2}{*}{ December } & $0.722^{* *}$ \\
\hline & $(0.025)$ \\
\hline
\end{tabular}

Born in September-December

$\begin{array}{lll}1.365^{* *} & 1.286^{* *} & 1.251^{* *} \\ (0.011) & (0.021) & (0.014) \\ & 0.013^{* *} & \end{array}$

Mother's years of schooling $x$ born in Sep.-Dec.

$(0.003)$

Cadre fathers $x$ born in

$0.108^{*}$

Sep.-Dec.

Professional fathers $x$ born in $0.238^{* *}$ Sep.-Dec.

$x$ born in Sep.-Dec. 
Table 1 The logistic regression of early school entry for one year on child's birth month (Continued)

\begin{tabular}{|c|c|c|c|c|}
\hline & Model 1.1 & Model 1.2 & Model 1.3 & Model 1.4 \\
\hline \multirow[t]{2}{*}{ Manual worker fathers $\times$ born in Sep.-Dec. } & & & & $0.413^{* *}$ \\
\hline & & & & $(0.030)$ \\
\hline
\end{tabular}

Notes: The numbers in parentheses are standard errors. ${ }^{*} p<0.01 ;{ }^{*} p<0.05 . N=197,102$. Omitted dummy variables as reference group are father's occupation as peasant, born in January (for Model 1.1), and born in January-August (for Model 1.2, Model 1.3, and Model 1.4). Estimates for intercepts and control variables, including child's year of birth, sex, sibship size, and rural-urban residence, are not presented in Table 1

likely to follow the cutoff date and more likely to start school earlier. We also construct interactive models based on Model 2.2 to test the interactive effect of parental socioeconomic status and being born just before the cutoff date on delayed school entry. The interaction terms in Models 2.3 and 2.4 in Table 2 show that high parental socioeconomic status facilitated the delay of school entry for May-August-born children.

\section{Alternative explanation}

The findings based on the 1992 Survey of the Living Situation of Chinese Children can help explain the variation in adult achievement by birth month that we found in the 2005 1\% Mini-census Survey data. Going back to our earlier findings from the 2005 1\% Mini-census Survey, we noticed that the lowest achievements were not observed among the July-August-born group. We now conjecture that a portion of children in this group voluntarily delayed school entry to avoid being disadvantaged by their younger age positions. Similarly, the highest achievement was not found in the September-October-born group. This was probably because this group was a mixture of those older at school entry and those voluntarily starting school ahead of schedule.

Therefore, we propose an explanation for the phenomenon of the cutoff date effect in China. Parents usually have a sense of their child's school readiness and weigh the possible costs and benefits of having the child start school late or early relative to the official cutoff date. Starting school either too early or too late is least preferred, because in the former situation, the child is not ready for school, and in the latter situation, the child may waste too much time. The cutoff date arbitrarily divides children born in different months in the same year into two groups, assuming that children born before the cutoff date are ready for school while those born after the cutoff are not. However, chronological age is not always the same as developmental age. Parents know their children best and may delay or speed up children's schooling age in this 1-year window. As a result of some parents' choice to avoid unnecessary delay, the percentage of "early entry" is high among September-December-born children. Similarly, "delayed entry" is low among children born after the cutoff date. At the same time, some parents may want to hold their child back because the child is less mature than his/her peers. If this child was born in September-December, parents can just follow the official cutoff date so as to have the child start school almost one year late and be counted as an "on-time entrant." Hence, the proportion of delayed entry was low among the September-December-born children despite their demand for entry at 
Table 2 The logistic regression of delayed school entry for one year on child's birth month

\begin{tabular}{|c|c|c|c|c|}
\hline & Model 2.1 & Model 2.2 & Model 2.3 & Model 2.4 \\
\hline \multirow[t]{2}{*}{ Mother's years of schooling } & $-0.045^{* *}$ & $-0.045^{* *}$ & $-0.068^{* *}$ & $-0.046^{* *}$ \\
\hline & $(0.002)$ & $(0.002)$ & $(0.002)$ & $(0.002)$ \\
\hline \multirow[t]{2}{*}{ Father's occupation: Cadre } & $-0.715^{* *}$ & $-0.715^{* *}$ & $-0.730^{* *}$ & $-0.937^{* *}$ \\
\hline & $(0.039)$ & $(0.039)$ & $(0.039)$ & $(0.053)$ \\
\hline \multirow[t]{2}{*}{ Professional } & $-0.666^{* *}$ & $-0.669^{* *}$ & $-0.684^{* *}$ & $-1.083^{* *}$ \\
\hline & $(0.062)$ & $(0.062)$ & $(0.062)$ & $(0.093)$ \\
\hline \multirow[t]{2}{*}{ Lower nonmanual worker } & $-0.320^{* *}$ & $-0.319^{* *}$ & $-0.323^{* *}$ & $-0.513^{* *}$ \\
\hline & $(0.028)$ & $(0.028)$ & $(0.028)$ & $(0.036)$ \\
\hline \multirow[t]{2}{*}{ Manual worker } & $-0.252^{* *}$ & $-0.253^{* *}$ & $-0.254^{* *}$ & $-0.469^{* *}$ \\
\hline & $(0.022)$ & $(0.022)$ & $(0.022)$ & $(0.027)$ \\
\hline \multirow[t]{2}{*}{ Birth month: February } & $0.070^{*}$ & & & \\
\hline & $(0.029)$ & & & \\
\hline \multirow[t]{2}{*}{ March } & $0.172^{* *}$ & & & \\
\hline & $(0.029)$ & & & \\
\hline \multirow[t]{2}{*}{ April } & $0.249^{* *}$ & & & \\
\hline & $(0.029)$ & & & \\
\hline \multirow[t]{2}{*}{ May } & $0.314^{* *}$ & & & \\
\hline & $(0.029)$ & & & \\
\hline \multirow[t]{2}{*}{ June } & $0.367^{* *}$ & & & \\
\hline & $(0.029)$ & & & \\
\hline \multirow[t]{2}{*}{ July } & $0.460^{* *}$ & & & \\
\hline & $(0.028)$ & & & \\
\hline \multirow[t]{2}{*}{ August } & $0.492^{* *}$ & & & \\
\hline & $(0.028)$ & & & \\
\hline \multirow[t]{2}{*}{ September } & $-0.711^{* *}$ & & & \\
\hline & $(0.031)$ & & & \\
\hline \multirow[t]{2}{*}{ October } & $-0.694^{* *}$ & & & \\
\hline & $(0.030)$ & & & \\
\hline \multirow[t]{2}{*}{ November } & $-0.662^{* *}$ & & & \\
\hline & $(0.031)$ & & & \\
\hline \multirow[t]{2}{*}{ December } & $-0.513^{* *}$ & & & \\
\hline & $(0.031)$ & & & \\
\hline \multirow[t]{2}{*}{ Born in May-August } & & $0.289^{* *}$ & -0.010 & $0.153^{* *}$ \\
\hline & & $(0.014)$ & $(0.021)$ & $(0.016)$ \\
\hline \multirow[t]{2}{*}{ Born in September-December } & & $-0.768^{* *}$ & $-0.772^{* *}$ & $-0.773^{* *}$ \\
\hline & & $(0.015)$ & $(0.015)$ & $(0.015)$ \\
\hline \multirow[t]{2}{*}{ Mother's years of schooling $\times$ born in May-Aug. } & & & $0.059^{* *}$ & \\
\hline & & & $(0.003)$ & \\
\hline \multirow[t]{2}{*}{ Cadre father $\times$ born in May-Aug. } & & & & $0.530^{* *}$ \\
\hline & & & & $(0.073)$ \\
\hline \multirow[t]{2}{*}{ Professional father $\times$ born in May-Aug. } & & & & $0.885^{* *}$ \\
\hline & & & & $(0.119)$ \\
\hline \multirow[t]{2}{*}{ Lower nonmanual worker father $\times$ born in May-Aug. } & & & & $0.492^{* *}$ \\
\hline & & & & $(0.050)$ \\
\hline
\end{tabular}


Table 2 The logistic regression of delayed school entry for one year on child's birth month (Continued)

\begin{tabular}{|c|c|c|c|c|}
\hline & Model 2.1 & Model 2.2 & Model 2.3 & Model 2.4 \\
\hline \multirow[t]{2}{*}{ Manual worker father $\times$ born in May-Aug. } & & & & $0.550^{* *}$ \\
\hline & & & & $(0.036)$ \\
\hline
\end{tabular}

Notes: The numbers in parentheses are standard errors. ${ }^{*} p<0.01 ;{ }^{*} p<0.05 . N=197,102$. Omitted dummy variables as reference group are father's occupation as peasant, born in January (for Model 2.1), and born in January-April (for Model 2.2, Model 2.3, and Model 2.4). Estimates for intercepts and control variables, including child's years of birth, sex, sibship size, and rural-urban residence, are not presented in Table 2

older ages but was not truly lower than for children born in other months. In sum, we can assume that parents would choose the best timing for their child's school entry if they were allowed to freely make such a choice. They would send children more mature than their peers to school earlier, so that these children could save time for other life transitions in the future, and they would hold back children developing more slowly, so that those children could avoid disadvantages due to their late maturity. In practice, however, given that only one school-starting date in September is offered by the school system each year, it is easier for parents of September-December-born children to manipulate the timing of their children's school entry. As a result, their children benefit either from the age position effect or from time saved for their futures. This explains why we can still observe higher achievement among those born between September and December in the adult population, even if the level of compliance with the cutoff date was low.

Our alternative explanation emphasizing flexibility of the timing of school entry for birth months after the cutoff date remains to be validated with more data. But this explanation fits the context of China better than the age position effect alone. However, there is still a puzzle that cannot be explained by our analysis above. Why do we observe the lowest adult achievements among March-born individuals rather than among individuals born in other birth months before the cutoff date? A disadvantageous combination of on-time entry, early entry, and delayed entry of the March-born group seems not to be the only explanation. We suspect that there might also be a selection of biological endowment in the timing of birth due to a potential correlation between

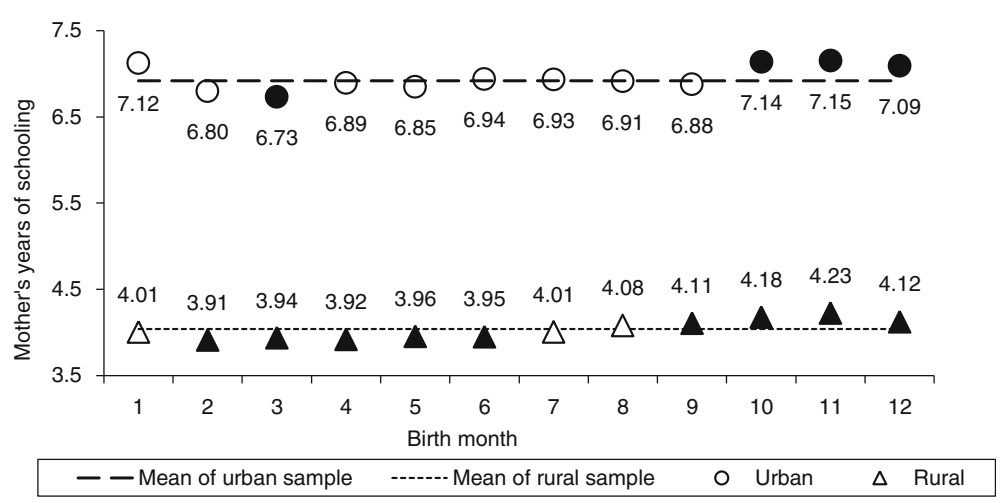

Fig. 6 Conditional means of mother's years of schooling by child's birth month and areas.Notes: Conditional means are predicted by an OLS regression model of mother's years of schooling on child's birth months (effective coding) for urban and rural samples separately. Dummy variables of child's birth year and provinces are controlled in the models. A solid triangle or circle marker represents that the value significantly differs from the grand mean at a significance level of 0.01 
seasonality of births and parental socioeconomic status. In Fig. 6, we compare the mean of mother's years of schooling by the child's birth month for rural and urban sample separately, using the 1992 Survey of the Living Situation of Chinese Children. In urban areas, we find that mothers of March-born children had significantly fewer years of schooling than mothers of children born in other months, while mothers of OctoberDecember-born children had more years of schooling than mothers of children born in other months. In rural areas, mothers of February-June-born children were found to be less educated, while mothers of September-December-born children were more educated. For a long time, most studies did not reveal a socioeconomic selection in birth timing. Dickert-Conlin and Elder (2010), for example, systematically examined the mother's and child's characteristics before and after the cutoff date and concluded that the birth timing around the enrollment cutoff date is almost random. However, a recent study by Buckles and Hungerman (2013) found that mothers of December-Januaryborn children in the USA had the lowest socioeconomic status, though their study could not explain this phenomenon. In contrast with the Buckles and Hungerman study, our study found that the lowest socioeconomic status was among mothers of spring-born children, rather than among mothers of winter-born children. We cannot explain why mothers with low socioeconomic status more often gave birth to a child around March while mothers of high socioeconomic status more often gave birth to a child between September and December. We tried to use mother's occupation and living arrangements of married couples as possible explanations using the 1992 Survey of the Living Situation of Chinese Children, but we did not find any association between these variables and the child's birth month. Therefore, our study only proposes that selection in birth timing could be a possible mechanism of the cutoff date phenomenon but cannot validate the mechanism.

\section{Discussion and conclusions}

Based on the 2005 1\% Mini-census Survey and the 1992 Survey of the Living Situation of Chinese Children, our study examines the birth-month variations of achievements among adults and of school starting ages among children of the same birth cohorts. Regarding the beneficial outcomes enjoyed by September-December-born individuals, we find some supportive evidence: September-December-born individuals started school at older ages on average at the beginning and attained higher achievements in the end, relative to those born before September. Taking the two findings together, the most likely explanation for the achievement gap is that the age premium enjoyed by late entrants persisted through the process of human capital accumulation into later life. However, when we closely examine the birth-month patterns of school starting ages and adult outcomes, we find that the two patterns do not fully match the pattern predicted by the age position effect, and there is a high level of noncompliance with the cutoff date in China. We argue that the variation in adult achievements did not result from persistence of the age position effect throughout one's educational process, as Liu and Li claimed. Instead, we offer an alternative explanation for the cutoff date effect: having a child born during the last third of a year gives parents a stronger incentive and greater flexibility with which to arrange the best timing of school entry for their child. In contrast, if the child was born during other months, especially in the first half of the year, parents faced more limited choices and tended to follow the official rule. 
Parents know their children best and can make better choices for their children than those imposed by a government rule. This may explain why children born after the cutoff date enjoy better outcomes than those born before it. In addition, we also find some evidence on the selection in the child's birth timing from mother's educational attainment.

The alternative explanation offered by our study does not necessarily exclude the age position effect as one possible mechanism for the cutoff date effect nor does it conflict with Liu and Li's finding that students who are younger than their peers may suffer academic disadvantages. Nevertheless, we question the magnitude and persistence of the age position effect that Liu and Li claimed in their study. More specifically, we argue that the initial disadvantage due to younger school starting age should not be blamed for the inequality of later educational achievement at the societal level. The timing of school entry is only a minor factor among various factors that contribute to large social inequalities for educational outcomes in China. In the mainstream stratification literature, there are many other factors that have been proven to be more important and to produce lasting effects on educational inequality, including class, gender, rural-urban division, and parental socioeconomic status and involvements. Even though there is an age-related performance difference at the beginning, the performance gap will narrow as children grow up. Moreover, there are huge heterogeneities across individuals and families. Smarter and faster developing early entrants do not necessarily lag behind and are able to narrow the initial biological gap quickly. Higher-status parents may have more resources to help a child with a younger school starting age to adapt to school learning. In addition, we also argue that the age-related disadvantage of early school entrants can be offset by an age-related advantage as they save more time for the future, given the early timing hypothesis from the life-course perspective.

We also question some policy implications suggested by Liu and $\mathrm{Li}$, such as introducing multiple entry dates for schooling and having a special institution evaluate children's school readiness. These strategies not only are costly to implement but also may introduce other forms of inequality while trying to reduce age-related inequality. As our study shows, high-status parents are more likely to break the age rule and manipulate the timing of school entry for their children. We can expect that if parents are allowed to freely choose the timing of school entry for their children, high-status parents may make the best use of it, while low-status parents may not. Thus, the policy may enlarge rather than reduce the achievement gap between children in low-status families and those in high-status families.

But there is one policy implication about which we agree with Liu and Li. Parents and teachers should pay attention to age-related differences in performance among primary and secondary school students. They should be more responsive to and more patient with children with younger school starting ages and thus help these children to build self-confidence and adapt to school.

This study empirically demonstrates how the cutoff date and legal minimum age of school entry specified by the Compulsory Education Law has influenced the timing of school entry as well as adult outcomes. The Compulsory Education Law not only makes basic education available to most Chinese children but also requires that they start school at nearly the same age. Nevertheless, the minor variations in school starting age due to being born in different months still affect adult achievements through 
the accumulation of advantages and disadvantages. Our study went beyond illustrating this cutoff date effect. It also proposes parental self-selection as an alternative explanation to the phenomenon of the cutoff date effect in the Chinese context.

Due to data limitation, we are not able to directly test the effects of children's school entry age on adult achievement outcomes. For the same reason, we do not know the relative importance of the age position effect, the early timing hypothesis, and parental self-selection as competing mechanisms for birth month variation in adult outcomes. We encourage future research, using richer data, to examine the causal mechanisms for the observed association we reported between birth month and adult achievements, as well the selection process into school entry timing.

\section{Abbreviations}

Aug.: August; Dec.: December; IV: Instrumental variable; OECD: Organization for Economic Co-operation and Development; Sep.: September

\section{Acknowledgements}

The authors thank Dr. Yongai Jin for her assistance on the analysis of the 2005 1\% Mini-census Survey and Cindy Glovinsky for her editorial assistance.

Funding

Financial support for this study was provided by National Social Science Foundation of China (Grant no. 15CRK021).

\section{Availability of data and materials}

Yu Xie and Chunni Zhang had full access to the 1992 National Sample Survey of Living Situation of Chinese Children. The 2005 1\% Mini-census Survey was available at Renmin University. The Stata codes and outputs for this study are available from Chunni Zhang.

\section{Author's Information}

Chunni Zhang is an assistant professor at Department of Sociology, Peking University, China.

Yu Xie is a professor at Center on Contemporary China, Princeton University, USA and Center for Social Research, Peking University, China.

\section{Authors' contributions}

Chunni Zhang and Yu Xie designed research; Chunni Zhang analyzed data; and Chunni Zhang and Yu Xie wrote the article. Both authors read and approved the final manuscript.

\section{Competing interests}

The authors declare no conflict of interest.

\section{Author details}

${ }^{1}$ Department of Sociology, Peking University, Beijing, China. ${ }^{2}$ Center on Contemporary China, Princeton University, Princeton, NJ, USA. ${ }^{3}$ Center for Social Research, Peking University, Beijing, China.

Received: 14 March 2018 Accepted: 19 April 2018

Published online: 26 April 2018

\section{References}

Angrist, Joshua D., and Alan B. Krueger. 1991. Does compulsory school attendance affect schooling and earnings? Quarterly Journal of Economics 121: 1437-1442.

Angrist, Joshua D., and Alan B. Krueger. 1992. The effect of age at school entry on educational attainment: An application of instrumental variables with moments from two samples. Journal of the American Statistical Association 87: 328-336.

Angrist, Joshua D., and Jörn-Steffen Pischke. 2009. Mostly harmless econometrics: An empiricist's companion. Princeton: Princeton University Press.

Baxter-Jones, Adam, and Peter Helms. 1994. Born too late to win? Nature 370 (6486): 186.

Bedard, Kelly, and Elizabeth Dhuey. 2006. The persistence of early childhood maturity: International evidence of longrun age effects. Quarterly Journal of Economics 121: 1437-1472.

Black, Sandra E., Paul J. Devereux, and Kjell G. Salvanes. 2011. Too young to leave the nest? The effects of school starting age. Review of Economics and Statistics 93 (2): 455-467.

Buckles, Kasey S., and Daniel M. Hungerman. 2013. Season of birth and later outcomes: Old questions, new answers. Review of Economics and Statistics 95 (3): 711-724.

Daniels, Sandra, Diane Shorrocks-Taylor, and Edwin Redfern. 2000. Can starting summer-born children earlier at infant school improve their national curriculum results? Oxford Review of Education 26: 207-220.

Dhuey, Elizabeth, and Stephen Lipscomb. 2010. Disabled or young? Relative age and special education diagnoses. Economics of Education Review 29: 857-872. 
Dickert-Conlin, Stacy, and Todd Elder. 2010. Suburban legend: School cutoff dates and the timing of births. Economics of Educational Review 29: 826-841.

Dobkin, Carlos, and Fernando Ferreira. 2010. Do school entry laws affect educational attainment and labor market outcomes? Economics of Educational Review 29: 40-54.

Edwards, Stephen. 1994. Born too late to win? Nature 370 (6486): 186.

Elder, Glen H., Jr. 1985. Perspectives on the life course. In Life course dynamics: Trajectories and transitions, 1968-1980, ed. G.H. Elder Jr., 23-49. Ithaca: Cornell University Press.

Elder, Glen H., Jr. 1987. War mobilization and the life course: A cohort of World War II veterans. Sociology Forum 2: 449-472.

Elder, Glen H., Jr. 1994. Time, human agency, and social change: Perspectives on the life course. Social Psychology Quarterly 57: 4-15.

Elder, Glen H., Jr. 1998. The life course as developmental theory. Child Development 69: 1-12.

Elder, Todd E., and Darren H. Lubotsky. 2009. Kindergarten entrance age and children's achievement: Impacts of state policies, family background, and peers. Journal of Human Resources 44: 641-683.

Fredriksson, Peter, and Björn Öckert. 2005. Is early learning really more productive? The effect of school starting age on school and labor market performance, Discussion Paper 1659, IZA (Institute for the Study of Labor).

Gledhill, Julia, Tamsin Ford, and Robert Goodman. 2002. Does season of birth matter? The relationship between age within the school year (season of birth) and educational difficulties among a representative general population sample of children and adolescents (aged 5-15) in Great Britain. Research in Education 68 (1): 41-47.

Liu, Dehuan, and Xuelian Li. 2015. Children born in July and August: A study on the age regulation of primary schoo admission and student's education access and development. Sociological Studies 6: 169-245 (in Chinese).

Mayer, Karl U., and Walter Müller. 1986. The state and the structure of the life course. In Human development and the life course: Multidisciplinary, ed. A. Soreson, F.E. Weinert, and L.R. Sherrod, 217-245. Hillsdale: Erlbaum.

McEwan, Patrick J., and Joseph S. Shapiro. 2008. The benefits of delayed primary school enrollment. Journal of Human Resources XLIII: 1-29.

Mühlenweg, Andrea M., and Patrick A. Puhani. 2010. The evolution of the school-entry age effect in a school tracking system. Journal of Human Resources 45: 408-440.

Musch, Jochen, and Simon Grondin. 2001. Unequal competition as an impediment to personal development: A review of the relative age effect in sport. Developmental Review 21 (2): 147-167.

Pidgeon, Douglas A. 1965. Date of birth and scholastic performance. Educational Research 8: 3-7.

Puhani, Patrick A., and Andrea M. Weber. 2008. Does the early birth catch the worm? Instrumental variable estimates of early educational effects of age of school entry in Germany. In The economics of education and training, ed. C. Dustmann, B. Fitzenberger, and S. Machin, 105-132. Heidelberg: Physica-Verlag.

Shearer, E. 1967. The effect of date of birth on teachers' assessment of children. Educational Research 10: $51-56$.

Thompson, D. 1971. Season of birth and success in the secondary school. Educational Research 14: 56-60.

Submit your manuscript to a SpringerOpen ${ }^{\odot}$ journal and benefit from:

- Convenient online submission

- Rigorous peer review

Open access: articles freely available online

High visibility within the field

- Retaining the copyright to your article

Submit your next manuscript at $\boldsymbol{s p r i n g e r o p e n . c o m ~}$ 